\title{
AN AHP APPLICATION TO WINE EVALUATION: RATING BASED ON THE CRITERIA FRAMEWORK OF THE METHOD ADOPTED BY BRAZILIAN SOMELIERS ASSOCIATION - ABS
}

\begin{abstract}
Wine has been related to economic and socio-cultural evolution of many civilizations. Yet, it is very difficult to determine its origin, which is believed to predate the use of writing. Since those ancient times, wine production has developed considerably, turning it into a large and complex market with a broad range of flavors, aromas and tastes, quite hard to evaluate or quantify. A wine evokes another, bringing to mind memories, however, each wine remains unique, be it for the grapes or blend of grapes, climate, type of soil, geographic region, or for the harvest. Specialists have been rating wines by tasting them and analyzing their visual, olfactory and gustatory aspects. Trade, increasingly globalized, uses scores of notable specialists to provide reference and assign a degree of prominence to the products. The objective of this study is the application of AHP methodology to evaluate and rank wines with a view to achieve greater accuracy in the process, which is based on highly subjective criteria.
\end{abstract}

Keywords: evaluate, wine, AHP, hierarchy.

\section{Introduction}

The Old World has prevailed for a long time in wine production. In the span of one generation, from the $80 \mathrm{~s}$ on, several wine producing countries of the New World made so much progress that they began to compete with great European classics. With expanding consumption market and globalization, product evaluation began to use different metrics. High scores and $1^{\text {st }}$ place in a wine competition, awarded by notable specialists, may mean significant marketing advantages, which will reflect in a premium positioning in the selling prices. Although these evaluations meet the existing demands, they are based on numerical-conceptual correspondence scales, adopting absolute scores and, therefore, are subject to inaccuracy due to the natural complexity and subjectivity involved.

\section{Literature Review}

Five decision-making methods by multiple criteria have been analyzed: Cross Tabulation; Evaluation based on rank; Weighted criteria; TOPSIS and AHP. The first 3 through Teknomo work (TEKNOMO, 2015) and TOPSIS through HWANG; LAI; and LIU (1993) and in an article published in 2014 by REN, H. and Yang, L., "Fuzzy Multiattribute Group Decision Making Method for Wine Evaluation Model". AHP characteristics meet more adequately the objective of this work, as it allows a pairwise comparison of the alternatives, in a simple and objective way, being less complex than a comparison of one alternative against several others at the same time. Furthermore, it always use relative ratings and not absolute ones.

\section{Objective}

The objective is the application of a hierarchical methodology to evaluating and ranking wines, giving a scientific contribution to the wine market. 


\section{Research Design/Methodology}

The base used was the criteria structure of Giancarlo Bossi method, adopted by ABS, whose criteria and sub-criteria are customary in most of evaluation sheets found in the wine sector around the world, and they have been described in this work based on literature sources of industry experts. Five renowned top experts were selected to measure their perception of relative weights and the relative importance of the criteria and sub-criteria, using AHP in all stages. Finally, 3 wines were compared by 5 other experts using AHP, considering the relative importance of the criteria and sub-criteria and perception weight of those five first top experts. The consistency test in the final matrix obtained a fully satisfactory degree.

\section{Data/Model Analysis}

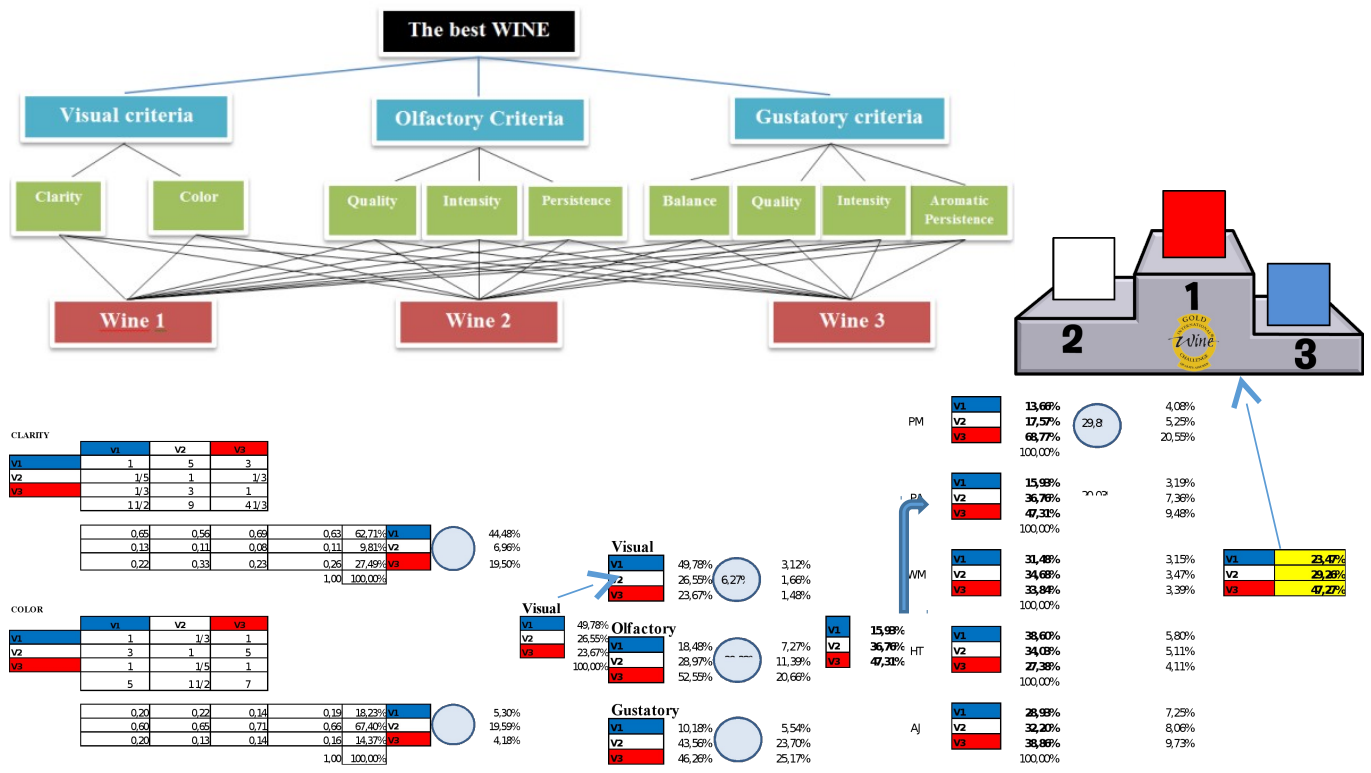

\section{Conclusions}

AHP is perfectly applicable to rank wines, with fully satisfactory consistency degree. Even though the wines are very close in quality, it is possible to obtain a more precise ranking, despite the subjectivity and complexity. Another important contribution in the development of a more accurate evaluation is the fact that the visual criteria weight in ABS sheet is $16 / 100$ and after using AHP, the weight is significantly reduced to $6 / 100$.

\section{Key References}

SAATY, T. L. The Analytic Hierarchy Process. New York: McGraw-Hill, 1980.

TEKNOMO, K. Analytic Hierarchy Process (AHP) Tutorial - Website http://people.revoledu.com/kardi/tutorial/AHP/. Acesso em 23 de dezembro de 2015.

ROBINSON'S, J. Wine Tasting Workbook. London: ConranOctoplus Limited, 2000. 